\title{
Récepteurs hépatiques à la somatotropine bovine et récepteurs mammaires à la prolactine et à l'IGF1 après injections de somatotropine bovine recombinée (rbST) chez la chèvre en lactation
}

\author{
C Disenhaus ${ }^{1}, \mathrm{H}$ Jammes $^{2}$, L Belair ${ }^{2}$ \\ 1 INRA, station de nutrition et alimentation, 16, rue Claude-Bernard, 75231 Paris Cedex 05; \\ 2 INRA, unité d'endocrinologie moléculaire, 78352 Jouy-en-Josas Cedex, France
}

\begin{abstract}
Summary - GH hepatic receptors and prolactinic and IGF1 mammary receptors in lactating goat injected with rbST. In lactating goats injected with rbST for 4 weeks, the specific binding of ${ }^{125} /$-bST on hepatic microsomes was significantly depressed versus control goats $(P<0.008)$, related to a decrease in both affinity and number of tree receptors. No difference was observed for the specific binding of ${ }^{125} / \mathrm{IGF} 1$ and ${ }^{125} \mathrm{I}-\mathrm{hGH}$ on mammary microsomes between treated and control goats. According to these results, no correlation was observed between milk production and receptivity of mammary cells.
\end{abstract}

Les mécanismes cellulaires impliqués dans le contrôle galactopoïétique exercé par la bST sont encore mal connus. Dans ce travail, sont analysées les modifičtions de réceptivités hépatique à la somatotropine et mammaire à la prolactine et à l'IGF1, consécutives aux injections de rbST chez la chèvre en lactation et reliées aux observations zootechniques décrites précédemment (Disenhaus et al, 1992).

Matériel et méthodes - Dix chèvres en $10^{\mathrm{e}}$ semaine de lactation sont sacrifiées après 4 semaines d'injections quotidiennes de $5 \mathrm{mg}$ de rbST (Upjohn, Lot 1). Le lot témoin $(T)$ n'a reçu aucune injection. Le foie et les glandes mammaires sont prélevés et immédiatement congelés. Les préparations microsomiales sont obtenues par centrifugation différentielle de l'homogénat tissulaire. Les différents ligands radio-iodés (bST et hGH, National Institute for Health; IGF1,
Amersham) ont une radioactivité spécifique de l'ordre de $100 \mu \mathrm{Ci} / \mu \mathrm{g}$. Les microsomes ( $400 \mu \mathrm{g}$ de protéines) sont incubés en présence de ligand radio-iodé $\left(10^{5} \mathrm{cpm}\right)$ et en absence (fixation totale, $\mathrm{FT}$ ) ou en présence de concentrations croissantes d'hormone non radio-iodée (fixation non spécifique, FNS). L'affinité et le nombre de récepteurs sont déterminés à partir des courbes de liaison spécifiques, selon les équations de Chang et Prusoff (1973).

Résultats et discussion - Dans la glande mammaire, la fixation spécifique de |'125|-IGF1 n'est pas modifiée par le traitement ( $: 4,91 \pm 1,7 \% ; T: 4,78 \pm$ $0,98 \%$ ). Les profils des courbes de liaison compétitive sont similaires (résultats non présentés) : la fixation spécifique se caractérise par une seule classe de récepteurs $(83,5 \pm 16 \mathrm{fmol} / \mathrm{mg}$ protéines) de forte affinité $\left(K_{\mathrm{d}}=1,44 \pm 0,7810^{-9} \mathrm{M}\right)$. Il en est de même pour la fixation spé- 
cifique de $\mathrm{I}^{125} \mathrm{IhGH}(\mathrm{I}: 9,6 \pm 2,32 \%$; $\mathrm{T}: \mathbf{8 , 5} \pm 1,17 \%)$ marquant les récepteurs prolactiniques. Aucune corrélation n'est observée entre la production laitière et la réceptivité des cellules mammaires. Aucune fixation spécifique de |'125/-bST n'a pu être détectée.

En revanche, la fixation spécifique de $\left.\right|^{125} \mid-b S T$ sur les microsomes hépatiques est significativement diminuée par le traitement (I: $5,96 \pm 0,73 \%: T$ : $9,97 \pm 2,11 \% ; P<0,008)$. Selon les courbes de liaison compétitive (fig 1), les variations de l'affinité $\left(l: K_{d}=\right.$

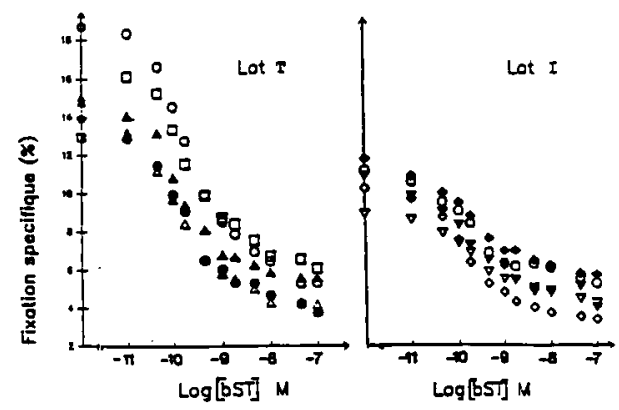

Fig 1. Courbes de liaison compétitives en présence de $\left.\right|^{125} \mathrm{I}-\mathrm{bST}\left(10^{5} \mathrm{cpm}\right)$ et de concentrations croissantes de bST non radioiodée sur des microsomes hépatiques de chèvres (lot l et $\mathrm{T}$ ). La radioactivité liée est exprimée en $\%$ de la radioactivité totale présente dans le milieu d'incubation. Chaque symbole représente un animal.
$0,95 \pm 0,1210^{10} \mathrm{M}: \mathrm{T}: K_{\mathrm{d}}=0,66 \pm 0,32 \times$ $10^{10} \mathrm{M} ; P<0,09$ ) et du nombre de récepteurs libres (1: $170 \pm 35 \mathrm{fmol} / \mathrm{mg}$ protéines; T : $254 \pm 147 \mathrm{fmol} / \mathrm{mg}$ protéines; $P<0,25)$ contribuent à cette diminution. Suite à un traitement de dissociation des complexes hormonerécepteur $\left(\mathrm{MgCl}_{2}, 3 \mathrm{M}, \mathrm{pH}\right.$ acide), la fixation spécifique de $\left.\right|^{125} \mathrm{JbST}$ sur les récepteurs totaux est similaire pour les 2 lots (I : $6,39 \pm 2,62 \%$; T : 7,18 \pm $2,29 \%$ ).

En conclusion, ces résultats soulignent l'action directe de la bST sur le foie par une augmentation de l'occupation des récepteurs. La glande mammaire de chèvre comme celle d'autres ruminants (Dehoff et al, 1988; Disenhaus et al, 1988), possède des récepteurs de haute affinité pour l'IGF1. Aucune modification de la liaison de l'IGF1 ne semble impliquée dans les variations observées de production laitière.

Cheng Y, Prusoff WH (1973) Biochem Pharmacol 22, 3099-3108

Dehoff $M H$, Elgin RG, Collier RJ, Clemmons DR (1988) Endocrinology 122, 2412-2417

Disenhaus C, Belair L, Diiane J (1988) Reprod Nutr Dev 28 (2A), 241-252

Disenhaus $C$, Hervieu J, Ternois $F$, Jammes $H$, Kann G, Sauvant D (1992) Ann Zootech 41, 97-98 